\title{
Mode of travel and the decision to allow children to walk or bike to schools-The Abu Dhabi experience
}

\author{
Masood A. Badri ${ }^{{ }^{*}}$, Abdulla M. Ustadi ${ }^{2}$, Lynne Pierson ${ }^{3}$, Mubarak Al Dramaki ${ }^{4}$ \\ ${ }^{1}$ Abu Dhabi Education Council, Unit of Research and Planning, Abu Dhabi, UAE; \\ *Corresponding Author: masood.badri@adec.ac.ae \\ ${ }^{2}$ Department of Health Authorities, Dubai, UAE \\ ${ }^{3}$ Abu Dhabi Education Council, Abu Dhabi, UAE \\ ${ }^{4}$ Abu Dhabi Education Council, Health Management, Abu Dhabi, UAE
}

Received 23 July 2012; revised 14 September 2012; accepted 21 October 2012

\begin{abstract}
The study investigates school travel to and from schools as perceived by parents in Abu Dhabi, United Arab Emirates. Far fewer children are cycling or walking to school, and more and more are being driven to school by car. Traffic conditions, environmental factors, distance to school, road's infrastructures, walking or biking with groups, schools efforts to educate children about active travel, and preferences of parents to accompany children to school were significantly perceived as important. The absence of active travel culture in the community was seen as a significant factor. Parent's gender, child's gender, child's grade level, number of cars owned by the family, nationality and number of children were significantly associated with parents' decisions to allow active travel to school. Results show that Abu Dhabi must establish aggressive strategic plans to promote active-commuting to school as the main mode of transportation. Current conditions in Abu Dhabi City are not conducive to active travel to school.
\end{abstract}

Keywords: Mode of Travel; Active Travel to School; Factors Affecting Active Travel; Walking to School; Biking to School; Abu Dhabi

\section{INTRODUCTION}

No studies to date have examined factors associated with travel to school among Abu Dhabi children. Abu Dhabi is the capital of the United Arab Emirates with a population of 1,967,659 according to the 2011 census. Abu Dhabi City accounts for $60.1 \%$ of the total population in the Emirate. With over 174,639 students (64\% in public schools, and $36 \%$ in private schools) and 248 public and private schools (49\% public schools, $51 \%$ private schools), Abu Dhabi is the largest Emirate in the United Arab Emirates. To keep pace with school demand, the government of Abu Dhabi built many new schools in the past 15 years (18 were built in 2010 and 2011 alone). The Abu Dhabi Education Council (ADEC) plans to build approximately 30 new schools over the next ten years.

Except for normal land offerings, the schools were built with little coordination between the local government, which approves new subdivisions, and Abu Dhabi Education Council (ADEC) which is responsible for building new schools to meet the demand for additional capacity. Starting in 2007, the local government authorities worked towards requiring local government authorities to prepare comprehensive plans that address such specific issues as housing, transportation, and infrastructure. In addition, the government required that plans be consistent with overall planning goals.

In 2011, Abu Dhabi central government called for adopting development plans that required coordination between ADEC and either local government authorities, i.e. with the goal of fostering cooperative relationships to help align school planning with decisions about residential development and the provision of infrastructure. Under this understanding, government authorities and ADEC must adopt strategies that address school sitting, enrollment forecasting, school capacity, infrastructure, co-location, joint use of civic and school facilities, and processes for dispute resolution.

Recently worldwide, school sitting and student transportation decisions have received increased attention due to the rise in childhood obesity and the search for ways to stem this epidemic [1-4]. ADEC has set up plans in coordination with the Department of Transport-Abu Dhabi (DTAD) and the Health Authority in Abu Dhabi (HAAD) to promote active travel to school to help ensure health and transport policies translating into increased walking and cycling, with associated benefits for 
health and the environment. The three parties believe that active school travel could be a prime opportunity to increase children's physical activity levels.

There is no data on active travel in Abu Dhabi to provide better planning. In June 2009, the three entities started work on an ambitious project to investigate school travel planning. The study aimed to identify what parents perceived as important determinants of students' travel to school. An earlier report by DTAD identified several factors causing traffic pollutions in Abu Dhabi. Of concern to the study is the fact that all the factors contribute one way or another to the mode of children's travel to school.

This research also forms the basis for identifying the most urgent areas of strategic improvements needed in Abu Dhabi, and to provide guidance for local authorities about how to work effectively with schools to promote more sustainable, safer and healthier patterns of travel. Even though the findings reported here have largely been derived from experience in Abu Dhabi City, it seems probable that many of the factors identified as being relevant to achieving and supporting more sustainable travel to school would also be relevant in other contexts and for other cities.

The Abu Dhabi community has never embraced an active travel culture. Until the writing of this research, there was not even a single file or document at the Ministry of Education, ADEC, DTAD or any of the (248) schools in Abu Dhabi related to walking or biking to school. Moreover, the researchers of this study checked with every school in Abu Dhabi, public or private as to whether anyone had ever designed a walk or bike to school brochure, organized an event dealing with walk or bike to school, or had been involved in any program dealing with the issue.

No record was found. Since its establishment in 1971, the Ministry or Education has never embraced the idea of actively encouraging a culture of active travel to school. This is also true with regard to ADEC. However, there are environmental awareness types of campaigns organized by the Abu Dhabi Environment Authority dealing with schools' green issues and sustainability; but not directed for active travel to schools.

Results from this research could strengthen existing evidence and enhance efforts to promote active travel to school. Understanding the factors that influence children's travel patterns is an essential first step in devising appropriate strategies to ensure their safety on the road, and the road environs. Several questions guided this research and related to Abu Dhabi:

- How do children get to and from school?

- What is the relationship between distance from home to school and mode of travel to school?

- What is the perception of road safety and built envi- ronment with regard to active travel to school?

- What is the perception of other important factors with regard to active travel to school?

- How present is the culture of active travel to school in the community?

- What are the significant travel factors affecting children's mode of travel to school in Abu Dhabi?

- What are the significant demographic factors affecting the decision to allow children to walk or bike to school in Abu Dhabi?

\section{LITERATURE REVIEW}

Since the current research designed a complete questionnaire derived from relevant previous work, it was deemed appropriate to present the literature background of the items used. Research to date fails to consider the potentially complex role of parent decision-making plays in controlling children's travel behaviors and how environmental characteristics interact with these processes [5-7]. Future research with different settings may be particularly helpful for unraveling the complexities of school travel behavior [8].

\subsection{Dependency on Cars}

In a number of Western countries, dependency on car use is evident in research into modes of school travel. This trend has been noted with concern by environmental groups, health authorities and schools across many of these countries. Research in the UK [9-11], USA [12,13], Australia [14] and Canada [15] has indicated that the proportion of children being chauffeured to school by parents has increased over the past few decades.

\subsection{Walking to School}

Proportions of children walking to and from school range from $4.2 \%$ to $25.0 \%$ [16-23]. However, in some special cases where students go home for lunch, the proportion has reached 90\% especially in Scandinavian countries $[4,24,25]$. The proportion of children walking and cycling to school varies considerably across countries $[25,26]$. In the United States, approximately 50 percent of children travel to school by car, with only $10 \%$ walking [27], whereas the majority of children walk or bike to school in Scandinavian countries $[24,25]$. Data from Australia, the US and the United Kingdom suggest active commuting to school to be on the decrease $[20,23$, 28].

\subsection{Active Travel and Physical Activity}

Research suggests that active commuting to school is an opportunity for children to achieve regular daily physical activity $[2-4,10,29]$. Many researchers believe that 
if more children walked or biked, it might be possible to lower children's health risks [13,31,32]. Many studies have reported higher levels of physical activity in children $[6,8]$ associated with active travel to school. In addition, regular participation in physical activity for young people can contribute to the enhancement of physical, psychological, and social well-being [29,33-35]; and may contribute to preventing excess weight gain $[36,37]$.

Positive contributions from walking and biking to schools to children's physical health have been the results of research in many countries, i.e., Russia [38]; the Philippines [30]; the US, [8]; and the UK [39].

McMillan [40] developed a conceptual framework to highlight factors that may influence parents' decisions about how school children travel to school. Parents are assumed to make the ultimate decision about whether their child can walk to school or not. The decision may be influenced by perceptions of the physical and social environments which combine with attitudes, beliefs, and perceptions of social norms about their child using active school travel. Within the framework, he identified an extensive array of correlates including demographic, individual and family factors, school factors, and social and physical environmental factors.

\subsection{Active Travel and Distance}

Researchers have studied many factors which influence walking or biking to school in children. Distance is shown to be a critical factor in children's travel walk [41-47]. Studies in the United States [40,44,48-50], the United Kingdom [45], and Australia [46,50] have shown distance to be a critical factor in children's travel. Others [46], note that those living within one mile of school are the most likely to walk. Travel time is an indirect reflection of distance. It is also a significant factor affecting students' travel modes [47,51-53].

\subsection{Traffic, Sidewalks and Safety}

Many researches included factors such as perceived neighborhood aesthetics and characteristics, related to the presence of traffic lights, pedestrian crossing improvements, and walking or bicycle paths $[7,46,54,55]$. Ewing et al., [56] and Boarnet et al. [7] found a positive association between the presence and condition of sidewalks and children's physical activity, while Mota et al. [1] found no association. The most significant determinants are perceived "stranger danger", or danger of assault, and danger from increased traffic [51,57-59].

Factors negatively influencing walking or biking to school include parental perceptions of heavy traffic within their neighborhood [51]. In a study by Martin and Carlson [60], parents express concern about traffic dangers and the risk of abduction or harassment. The studies have shown that distance, traffic, and crime are three key factors preventing students from walking/biking to school $[5,7,61]$. Lack of pedestrian infrastructure such as sidewalks was sighted in many studies $[7,42,62]$. Some studies noted reduced schools' roles have traditionally played in communities not accepting active travel to schools by parents [63].

\subsection{Built Environment}

The built environment appears to exert a significant effect on mode of travel to school [64]. Many studies examined the relationship between certain aspects of the built environment and choice of school travel mode [7,42, 43,45,54]. Around schools, car congestion during peak arrival and departure times creates a dangerous environment for those children who walk, cycle or catch public transport $[7,59,69,70]$. Research shows that in many countries, traffic jams connected to the school journey have created serious problems [11]. Driving children to school contributes to air pollution at a greater rate than longer urban trips [72].

There are no statistics in Abu Dhabi that directly categorizes sources of pollution in the morning or during other times of the day. There are many research studies that correlate mode of travel to school to personal or familial variables of children's commuting behavior to school $[46,47,54,73,74,76]$. Research results have been inconsistent showing that boys are more likely to walk to school in comparison to girls [52,74,77-79], but not always $[19,22,68,80]$. Some found that girls are less likely to walk than boys with the differences being most prominent at younger ages $[68,80]$ and in suburban areas $[81$, 82].

\subsection{Personal and Demographic Factors}

Literature review results also show that students' travel behavior to school is affected by many potential factors such as household income and location [52,82]. Household factors such as car ownership and parents driving to work also affect mode choice [76]. With regard to children's age, some findings show that younger children are more likely to walk to school [60]; while others show that older children are more likely to walk to school $[20,22]$. With regard to ethnic background, some research in the US noted that Hispanic and/or Black children are more likely to walk to school [22,51]. (Note: in this study we use nationality as a proxy to ethnic background). Household factors such as car ownership and parents driving to work also affect mode choice [76].

With regard to household income, studies show that mode of transportation is affected by household income [17]. In a study in Canada, [17] found that the proportion 
of students who walked to school was significantly higher among those whose income was less than $\$ 30,000$. The percentage of students who used public transportation was significantly lower among the students who had a household income between $\$ 30,000$ and $\$ 60,000$ in comparison to the higher and lower groups.

The proportion of students who were driven to school was significantly higher among students whose household income was greater than $\$ 60,000$ in comparison to the lower two income groups. There is evidence that the work status of parents is also associated with walking and biking to school $[77,78]$. Others showed that a small change in school starting time affected the travel patterns of every household member $[84,85]$. Travel models that incorporate household interactions have shown that the presence of children affects adult activity and travel scheduling. Research suggests that parental time constraints need to be addressed if policymakers hope to increase rates of active school travel [77,78,82].

The current study will be the first attempt to better understand the determinants of active travel to school in Abu Dhabi. In spite of referring to "community culture" indirectly in many studies relative to active travel to school $[46,86]$, none of the research reviewed isolated the factor directly as a determinant of active travel to school. In addition, none tried to test the contribution of each of the different factors to the decision of parents of allowing children to actively travel to school. The current research will strictly take the views of parents with regard to mode of travel to school and the decision to allow children to walk or bike to school.

\section{METHODS}

\subsection{Design and Development of the Survey}

From extensive review of literature related to children's travel to school, a survey consisting of 38 items was designed. The items were related to preference of parents to accompany the child to school, the culture of walking and biking to school, the environmental factors, the distance factors (minimum distance and actual distance), the safety factors (community conditions, traffic conditions, and road conditions), safety factors, the infrastructure of roads and lands to school, the school efforts in teaching about walking and biking to school, the form of walking and biking (walking or biking in a group), child's peers attitude towards walking or biking, and parents' beliefs of the benefits of walking and biking. Two items were also added to reflect the decision of parents to allow their children to walk or bike to schools.

A focus group of 14 members was invited to a meeting that took 3 hours of discussions. The focus group consisted of Head of Research in ADEC, Head of School Operations in ADEC, 6 parents, 4 school principals and a representative of the Abu Dhabi Road \& Transport Authorities. The results of the literature searches were presented to the group. Each item was discussed for its suitability in the Abu Dhabi study. Most of the parents in the focus group insisted that even with most travel to school factors being "satisfied", parents might not let their children walk or bike to school. They insisted that the questionnaire should contain questions regarding the "absence of the culture of walking or biking to school in Abu Dhabi”. They noted that many parents perceived walking or biking to school in Abu Dhabi as "not a normal habit”, and that other children or peers might make fun of them if they walked or biked to school. As a result, two items were added related to the culture of walking and the culture of biking to school in Abu Dhabi. In addition, two items were added related to the children's feelings that their peers might make fun of them if they walked or biked to school.

Many items were deleted from the survey to make it shorter. A total of 28 items remained in the final draft of the survey. Parents were asked to state their opinion as to level of agreement with each statement on a 5 point Likert scale ranging from $(1=$ strongly disagree to $5=$ strongly agree). Face validity of the survey was established by developing the survey based on a comprehensive review of the current literature. After designing the final instrument, a panel of researchers and the ADEC School Guardian Committee reviewed the survey and determined content validity.

To establish stability and reliability, the hard copy instrument was conducted with 32 parents from one district in the Emirate of Abu Dhabi (Al Karama) and then repeated one week later. The results yielded a mean correlation of 0.927 . Scale reliability was measured using the Cronbach alpha coefficient of reliability for the scales in the survey. Results of these analyses showed that the alphas for the different scales were acceptable [Decision to allow children to walk or bike to school (0.751), safety (road conditions, 0.802), safety (community conditions, 0.722 ), safety (traffic conditions, 0.718 ), environmental factors (0.778), minimum distance to school (0.778), actual distance to school (one item only), belief of parents of health benefits of walking or biking to school (0.802), road and school infrastructure and facilities (0.707), walking to school in groups (0.849), school teaching about active travel to school (0.712), culture of walking or biking (0.961), and children's peer's reaction to walking and biking $(0.885)]$.

The questionnaire further included questions about the child and the parent completing it. It included child's gender, nationality, grade level at school, school type, parent's highest academic education, number of children, family income level, and the number of cars in the household. Some questions also requested information 
about mode of transportation (taxi, school bus, public bus, car with a friend, car with parents, biking, walking), distance from school (8 choices ranging from less than 1 kilometer to more than 20 kilometers), time to school (8 choices ranging from less than 5 minutes to more than 60 minutes), number of cars owned by the family.

\subsection{Participants}

The participants for this study were parents of children of public and private schools in the City of Abu Dhabi. Parents of all public and private schools were invited to participate in this study. The survey was available for three weeks online on the ADEC website. A total of 1344 parents participated in the study. However, many questionnaires were not completed fully. A total of 1145 usable questionnaires were utilized for this study. Students' ages ranged from 4 to 18 years of age. They attended KG levels to Grade 12.

\subsection{Study Hypotheses}

For each scale, the summated score will be used in further analysis. Simple descriptive statistics will be computed for all constructs. To answer the questions raised by this study and related to factors affecting the mode of transportation to use to travel school, several hypotheses are proposed.

H1: Decision to allow children to walk or bike has significant effect on mode of transportation.

H2: Safety (road conditions) has significant effect on mode of transportation.

H3: Safety (community conditions) has significant effect on mode of transportation.

H4: Safety (traffic conditions) has significant effect on mode of transportation.

H5: Environmental factors have significant effect on mode of transportation.

H6: Minimum distance to school has significant effect on mode of transportation.

H7: Actual distance to school has significant effect on mode of transportation.

H8: Belief of parents of health benefits of walking or biking to school has significant effect on mode of transportation.

H9: Roads' and schools' infrastructure and facilities have significant effect on mode of transportation.

H10: Walking to school in groups has significant effect on mode of transportation.

H11: School teaching about active travel to school has significant effect on mode of transportation.

H12: Culture of walking or biking to school has significant effect on mode of transportation.

H13: Children's peer's reaction to walking and biking has significant effect on mode of transportation.
H14: Preference to accompany child to school has significant effect on mode of transportation.

To explore the effect of familial and demographic features on the decision of parents to allow the child to walk or bike to school eight hypotheses were proposed.

H15: Parent's gender has significant effect on decision to allow the child to walk or bike to school.

H16: Child's gender has significant effect on decision to allow the child to walk or bike to school.

H17: Child's grade level has significant effect on decision to allow the child to walk or bike to school.

H18: Parent's highest academic degree attainment has significant effect on decision to allow the child to walk or bike to school.

H19: Family income has significant effect on decision to allow the child to walk or bike to school.

H20: Type of school has significant effect on decision to allow the child to walk or bike to school.

H21: Number of cars per household has significant effect on decision to allow the child to walk or bike to school.

H22: Parent's nationality has significant effect on decision to allow the child to walk or bike to school.

H23: Number of children in the family has significant effect on decision to allow the child to walk or bike to school.

\subsection{Analysis Methods}

For the familial and demographic factors, descriptive statistics will be provided. Descriptive statistics will also be provided for the factors affecting the mode of travel to school. For H1 to H14, a series of ANOVA runs will be performed for each of the scales with regard to mode of transportation to school. In addition, for H15 to H23, further ANOVA tests will be carried out to test the effect of other demographic factors on the decision to allow the child to walk or bike to school.

\section{RESULTS}

\subsection{Mode of Travel to School}

Figure 1 shows most common modes of travel to school. Results show that the two most commonly used mode of transportation to school are by car (45\%) and by the school bus (38.1\%). Walking $(6.8 \%)$ or biking $(2.5 \%)$ to school combined, account for (9.4\%) only. There are also portions of children that use public transportation such as taxis $(2.3 \%)$ and buses (5.2\%). For those who walk or bike to school, we note that $85 \%$ of them take less than 30 minutes to get to school, and some of them (14\%) live further than 5 kilometers from the school. In addition, $54 \%$ of them are UAE nationals, $14 \%$ are from other Arab nationalities, while $13.1 \%$ are westerners. We also note that $73.6 \%$ of them are boys. There is no obvious 
pattern as to which age (grade level) walks or bikes more often; however, more children from grade 1, 2 and 3 walk or bike to school. Most of these children live in closed residential compounds not too far from their schools and with less traffic encountered during the travel to school. It is noted that $55.1 \%$ of this category of children attend private schools. Further analysis show that for those that take taxis to school, more than $46 \%$ of them live 30 minutes or more away from the school. For those children that have to travel less than 3 kilometers to get to the school (27.2\%), only $24.1 \%$ of them walk or bike to school, while $49.8 \%$ of them ride a car to school, and $20.6 \%$ take the school bus. It is noted also that $94.9 \%$ of those children reach school in less than 30 minutes. It should be noted, too, that all of the families in this category own 1 car at least. About $54.2 \%$ of the children are UAE nationals, and $59.9 \%$ of them are boys. In addition, $49.3 \%$ of them attend grades 1,2 or 3 and about 20\% attend grade 9 or above. It should be noted also that $62.8 \%$ of them attend private schools. About 65.3 percent of the children travel less than 10 kilometers. Travel to school takes at least 20 minutes for $51.9 \%$ of the children. It takes less than 30 minutes for $73.4 \%$ of the children. On average, most families have 1 or 2 cars (61.8\%). Most parents have bachelor degrees (43.4\%), while $38.2 \%$ hold less than a college degree. Male parents account for $51 \%$ of the respondents; and male children account for $58.3 \%$ of the total children. Parents, whose children attend private schools, account for 69.1 percent of the total number of parents. Most parents participating in the survey are from the UAE (45.3\%), and from other Arab countries (29.9\%). Only 7.5\% parents come from Europe, North America or other Western countries.

\subsection{Factors Affecting Mode of Travel}

Descriptive statistics (summated mean and standard deviation) of the factors or dimensions that affect the decision to allow the child to walk or bike to school is given in Table 1. The table also provides figures for the percentage of parents that answered "strongly agree" or "agree" to each of the items. The remaining percentage of parents answered "strongly disagree", "disagree" or "unsure". In other words, the percentages portray two choices on a 5-point scale. For those parents that drive their children to school, about $74.6 \%$ prefer doing so since the school is on his/her way to work. More than $87.5 \%$ of parents note that the culture of walking or biking to schools in Abu Dhabi is not strong. In addition, $79.8 \%$ of them feel that the driving public (traffic) are not used to slowing down during student crossings.

A large percentage of parents (78.8\%) point to environmental factors (i.e. weather and smog or pollution). Even though, $81.7 \%$ of parents refer to actual distance to school for being too far for walking to school, a large percentage believe that the option to walk to school $(80.9 \%)$ or bike to school $(75.8 \%)$ should be a favorable option if the child is within 1 kilometer (or 0.621 miles) of the school.

With regard to route to school safety, parents feel that a traffic condition is the most serious concern (i.e. busy traffic (86.2\%) and crossing signal lights (98.7\%)). On the other hand, the least severe condition is noted to be community related variables such as local community (71.8\%), violence/harassment (71.3\%), and location of the school (71.4\%). Road conditions are also considered as concerns to parents (i.e. unsafe route to school (82\%), and dangerous roads to cross (73.4\%)). It should be taken as a point of concern that parents attribute mode of transportation to other factors other than infrastructure of roads on route to the school. Only $49.6 \%$ feel that they would allow the child to bike to school if bicycle lanes are provided. Meanwhile, only $65.5 \%$ of the parents feel that if sidewalks are improved, they might consider allowing their children to walk to school.

Most parents agree that the schools do not encourage children to walk or bike to school (81.7\%), and schools do not have plans to educate students on the benefits of walking or biking (79.8\%). Parents also do not feel strongly that their children's friends might make fun of them if they walked (55.2\%) or biked (69\%) to school. Results also show that walking in groups might not be a reason for their decision to allow their children to walk to school, as only (52.2\%) agree with that statement. However, more parents feel that the children's peers might make fun of them if they biked to school (69\%). In other words, walking is more acceptable than biking.

With regard to the physical activity benefits, $75.9 \%$ parents believe that the health of children could be improved by encouraging more walking or biking. In addition, 75.3\% parents believe that if conditions are right, walking to school is specifically good for the health of the child. With regard to the direct questions relating to the decision of allowing the child to walk or bike to school, $77.9 \%$ of parents feel that under the current circumstances, they won't be happy allowing their children to walk or bike to school. However, only $60.8 \%$ of parents insist that they would not let their children to walk to school under any circumstances.

\subsection{Testing Hypotheses (Mode of Transportation and Factors of Travel)}

Table 2 provides the one way analysis of variance (ANOVA) results of testing the effect of parent perception with regard to factors of active travel to school or the mode of transportation to school. The decision to allow the child to walk or bike to school has a significant effect on the mode of travel selected $(F=15.66)$. For the 
Table 1. Parents' perceptions of factors affecting their decision to allow children to walk or bike to school—and Cronbach alpha.

\begin{tabular}{|c|c|c|c|}
\hline \multicolumn{2}{|r|}{ Factors affecting decision to allow children to walk or bike to school } & \multirow{2}{*}{$\begin{array}{c}\text { Mean (standard } \\
\text { deviation) }\end{array}$} & \multirow{2}{*}{$\begin{array}{c}\begin{array}{c}\text { Percent agree or } \\
\text { strongly agree }\end{array} \\
74.6 \% \\
69.9 \%\end{array}$} \\
\hline $\begin{array}{l}(1) \\
\bullet \\
\bullet\end{array}$ & $\begin{array}{l}\text { Preference to accompany the child to school } \\
\text { Preference to drive child to school because it is on my way to work } \\
\text { Preference to accompany child to school every day }\end{array}$ & & \\
\hline $\begin{array}{l}(2) \\
\bullet \\
\bullet\end{array}$ & $\begin{array}{l}\text { Culture of walking or biking to school }(0.961) \\
\text { Culture of "traffic slowing down in school areas during student crossings" } \\
\text { Culture of "walking" or "biking" to school is not strong }\end{array}$ & 4.037 (0.789) & $\begin{array}{l}79.8 \% \\
87.5 \%\end{array}$ \\
\hline $\begin{array}{l}(3) \\
\bullet \\
\bullet\end{array}$ & $\begin{array}{l}\text { Environmental factors ( } 0.778 \text { ) } \\
\text { Preference for not letting walk (exposed to smog/car pollution) } \\
\text { I cannot allow my child to walk to school because of weather conditions }\end{array}$ & 3.739 (0.991) & $\begin{array}{l}78.8 \% \\
77.3 \%\end{array}$ \\
\hline $\begin{array}{l}(4) \\
\bullet \\
\bullet\end{array}$ & $\begin{array}{l}\text { Distance-Minimum distance from school (0.778) } \\
\text { Should have the option of walking to school if they live within } 1 \text { kilometer } \\
\text { Should have the option of biking to school if they live within } 1 \text { kilometer }\end{array}$ & 3.838 (0.983) & $\begin{array}{l}80.9 \% \\
75.8 \%\end{array}$ \\
\hline (5) & $\begin{array}{l}\text { Distance-Actual distance to school } \\
\text { The school is too far for my child to walk or bike to school }\end{array}$ & 3.885 (0.899) & $81.7 \%$ \\
\hline $\begin{array}{l}(6) \\
\bullet \\
\bullet\end{array}$ & $\begin{array}{l}\text { Safety—Road conditions }(0.802) \\
\text { The route to school is not safe } \\
\text { The roads are too dangerous }\end{array}$ & $3.832(0.796)$ & $\begin{array}{l}82.0 \% \\
73.4 \%\end{array}$ \\
\hline $\begin{array}{l}(7) \\
\bullet \\
\bullet\end{array}$ & $\begin{array}{l}\text { Safety-Community conditions ( } 0.722 \text { ) } \\
\text { The local community is not safe enough to allow my child to walk to school } \\
\text { Unsafe to walk to school (violence/harassment) } \\
\text { School located in area (discourages me from allowing my child to walk to school) }\end{array}$ & 3.011 (0.894) & $\begin{array}{l}61.8 \% \\
61.3 \% \\
61.4 \%\end{array}$ \\
\hline $\begin{array}{l}(8) \\
\bullet\end{array}$ & $\begin{array}{l}\text { Safety-Traffic conditions }(0.718) \\
\text { Has to travel along and/or cross a road with busy traffic } \\
\text { Has to cross many light signals }\end{array}$ & 3.945 (0.998) & $\begin{array}{l}86.2 \% \\
89.7 \%\end{array}$ \\
\hline $\begin{array}{l}(9) \\
\bullet \\
\bullet\end{array}$ & $\begin{array}{l}\text { Infrastructure of roads and land to school }(0.707) \\
\text { If a bicycle lane is provided, I will let my child bike to go to school } \\
\text { If sidewalks are improved, I might consider allowing my child to walk to school }\end{array}$ & 3.297 (0.884) & $\begin{array}{l}49.6 \% \\
65.5 \%\end{array}$ \\
\hline $\begin{array}{l}(10) \\
\bullet\end{array}$ & $\begin{array}{l}\text { School efforts to teach about walking or biking to school ( } 0.712) \\
\text { School encourages children to walk to school (R) } \\
\text { School does not have plans to educate students on the benefit of walking or biking }\end{array}$ & 3.668 (0.859) & $\begin{array}{l}81.7 \% \\
79.8 \%\end{array}$ \\
\hline $\begin{array}{l}(11) \\
\bullet\end{array}$ & $\begin{array}{l}\text { Walking or biking to school with a group ( } 0.849) \\
\text { If my child is with a group of friends, I would let him bike to school } \\
\text { If child walks in groups/accompanied by an adult, I might let him walk to school }\end{array}$ & 3.149 (0.998) & $\begin{array}{l}52.2 \% \\
69.5 \%\end{array}$ \\
\hline $\begin{array}{l}(12) \\
\bullet\end{array}$ & $\begin{array}{l}\text { Child's peers attitude to walking or biking to school ( } 0.885) \\
\text { Child might not feel comfortable walking (his friends night make fun of him) } \\
\text { Child might not feel comfortable biking because his friends night make fun of him }\end{array}$ & 3.213 (0.894) & $\begin{array}{l}55.2 \% \\
69.0 \%\end{array}$ \\
\hline $\begin{array}{l}(13) \\
\bullet \\
\bullet\end{array}$ & $\begin{array}{l}\text { Parent's belief about the benefits of walking/biking to school }(0.802) \\
\text { Health improves by encouraging more school students to walk or bike to school } \\
\text { If conditions are right, I think walking to school is good for the health of my child }\end{array}$ & 3.658 (0.969) & $\begin{array}{l}75.9 \% \\
75.3 \%\end{array}$ \\
\hline (14) & $\begin{array}{l}\text { Decision to let child walk or bike to school }(0.751) \\
\text { I will not let my son walk or bike to school under any circumstances } \\
\text { In the current circumstances, I am happy if my child walks or bikes to school (R) }\end{array}$ & 3.554 (0.991) & $\begin{array}{l}60.8 \% \\
77.9 \%\end{array}$ \\
\hline
\end{tabular}

13 factors, the calculated $\mathrm{F}$ values are significant at the (0.05) level with regard to 9 of them. Thus, the related hypotheses are supported. The highest significance (highest $F$ values) is observed with regard to actual distance to school ( $F=24.919)$; preference of parents to accompany their children to school $(\mathrm{F}=15.06)$ because the school is on their way to work, or other reasons; and safety related issues with traffic conditions $(\mathrm{F}=11.828)$.

Other factors that have significant effect on the mode of travel to school include the absence of culture of walking or biking to school ( $\mathrm{F}=8.940$ ), environmental factors ( $\mathrm{F}$ $=4.733)$, school efforts in teaching about walking or biking to school $(\mathrm{F}=4.155)$, infrastructure of the route to school $(\mathrm{F}=11.286)$, and walking or biking in a group. As a result, hypotheses H1, H4, H5, H7, H9, H10, H11, H12, and H14 are supported. On the other hand, the safety issue related to road conditions, the minimum distance to school necessary for the option to walk or bike to school, parent's belief about the benefits of walking or biking to school, safety factors related to community conditions, 
and the child's peer's attitude to walking or biking to school. As a result, hypotheses H2, H3, H6, H8, and H13 are not supported.

\subsection{Testing Hypotheses (Decision to Allow and Other Factors)}

Table 3 provides results of ANOVA tests of the effects of familial and demographic features on the decision of parents to allow the children to walk or bike to school. For the nine hypotheses related to the familial and demographic features, three hypotheses were not supported, H18, H19, and H20. There is no statistical evidence that academic attainment of parents or their family

Table 2. ANOVA of mode of travel and factors.

\begin{tabular}{|c|c|c|}
\hline Variables & $\mathrm{F}$ & Sig. \\
\hline $\mathrm{H}_{1}$. Decision to allow walk or bike & 15.66 & 0.001 \\
\hline $\mathrm{H}_{2}$. Safety-Road conditions & 1.281 & 0.263 \\
\hline $\mathrm{H}_{3}$. Safety-Community conditions & 1.619 & 0.109 \\
\hline $\mathrm{H}_{4}$. Safety-Traffic conditions & 11.828 & 0.001 \\
\hline $\mathrm{H}_{5}$. Environmental factors & 4.733 & 0.001 \\
\hline $\mathrm{H}_{6}$. Distance-Minimum distance & 1.715 & 0.114 \\
\hline $\mathrm{H}_{7}$. Distance-Actual distance & 24.919 & 0.001 \\
\hline $\mathrm{H}_{8}$. Parent's belief about benefits & 1.775 & 0.101 \\
\hline $\mathrm{H}_{9}$. Infrastructure of roads (route) & 11.286 & 0.001 \\
\hline $\mathrm{H}_{10}$. Walking/biking with a group & 3.918 & 0.001 \\
\hline $\mathrm{H}_{11}$. School efforts to teach about & 4.155 & 0.001 \\
\hline $\mathrm{H}_{12}$. Culture of walking or biking & 8.940 & 0.001 \\
\hline $\mathrm{H}_{13}$. Child's peers attitude & 1.954 & 0.077 \\
\hline $\mathrm{H}_{14}$. Preference to accompany & 15.069 & 0.001 \\
\hline
\end{tabular}

Table 3. Parents' decisions and demographics.

\begin{tabular}{lcc}
\hline \multicolumn{1}{c}{ Variables } & $\mathrm{F}$ & Sig. \\
\hline $\mathrm{H}_{15}$. Parent's gender & 14.369 & 0.001 \\
$\mathrm{H}_{16}$. Child's gender & 13.965 & 0.001 \\
$\mathrm{H}_{17}$. Child's grade level & 3.783 & 0.001 \\
$\mathrm{H}_{18}$. Academic degree & 1.968 & 0.081 \\
$\mathrm{H}_{19}$. Family income & 1.167 & 0.319 \\
$\mathrm{H}_{20}$. School type & 0.569 & 0.451 \\
$\mathrm{H}_{21}$. Number of cars owned & 2.387 & 0.049 \\
$\mathrm{H}_{22}$. Nationality & 14.449 & 0.001 \\
$\mathrm{H}_{23}$. Number of children & 2.069 & 0.020 \\
\hline
\end{tabular}

income have any significant effect on the decision of parents to allow the child to walk or bike to school. In addition, the schools being public or private have no significant effect either.

Analysis of variance of the thirteen dimensions and the seven modes of transportation to school (see Figure 1) shows that all factors hypothesized are significant at the (0.05) level except for five factors of minimum distance to for deciding to allow to walk or bike, road conditions, infrastructure of roads and lands, children's peers attitude towards walking of biking to school, and parent's belief about the benefits of walking or biking to school.

\section{DISCUSSIONS}

In the city of Abu Dhabi, like many other metropolitan areas, there has been an increasing trend towards vehicular modes for home-school travel, and the school journey by car has become a significant feature of daily life for many families. Meanwhile the city suffers from air pollution crisis and traffic congestion. Most of its districts suffer from the fact that schools are not distributed efficiently. In Abu Dhabi, a variety of barriers exist for children navigating to school by foot or bike. Results also show the desire of parents to protect their children from unsafe roads by driving them to school. Other results show parents' concerns with regard to increased air pollution from car emissions and greater traffic congestion around the schools. In addition, the increasing parental fear of danger from strangers and assault is placing even more restrictions on children's mobility.

Results show that in Abu Dhabi, only 9.4 percent of children walk or bike to school. Nearly 45 percent of all school-aged children are driven to school by their parents. This contrasts sharply with the Abu Dhabi Education Council's vision and expectation of letting children attend nearby schools to encourage walking or biking to school. ADEC has established expectations for almost 90 percent of children living within two kilometers of their school walked or biked to school. However, results show that less than 15 percent of school children living within two kilometers of school walk or bike. The reliance on school bus for transportation has also peaked with more than $38.1 \%$ of parents pointing to that mode. In spite of all the efforts to improve public transportation, the per-

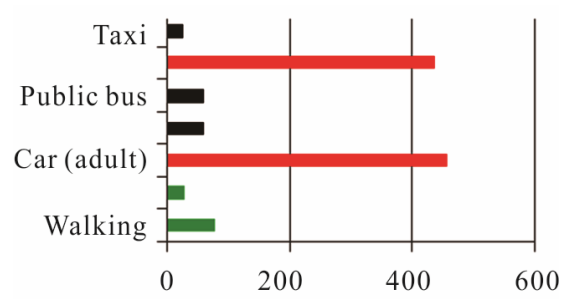

Figure 1. Mode of travel to school. 
centage of students who used public transportation was significantly lower compared to any mode of transportation (only 2.2\%).

Compared to countries like the US [27,73], Australia [74], Switzerland [4], and other Scandinavian countries $[24,25]$ the number of children walking or cycling to school in Abu Dhabi is relatively low. The vast majority of Abu Dhabi children attend schools that are not easily accessible from home via active transport. Consequently, the median straight-line distance between home and school in this study was about 3 - 5 kilometers and considerably longer than reported, for example, by other studies from other countries [76] or Australia [74].

This low reliance in active travel to school coincides with results from several studies that pointed to the rise in childhood obesity among children. Many reports from health authorities in Abu Dhabi $[66,67]$ show that Abu Dhabi children are not getting the recommended amount of physical activity, In addition to health concerns, the increase in the number of children being driven to school by their parents directly affects traffic congestion. Figures from the Health Legislation and School Health in the UAE point out that more than 50 percent of the children in the UAE are considered obese.

According to a report by the Health Authority in Abu Dhabi (HAAD) in 2010, it noted that 30 per cent of school children in Abu Dhabi were overweight or obese and 70 per cent of them are likely to stay overweight or obese as adults. There are no statistics on how much school-related traffic accounts for pollution of all morning peak hour traffic. Both ADEC and ADRT believe that by reducing the number of parents driving children to school, one could expect to relieve morning peak hour delays and congestion. There is evidence of the effect of work status of parents as it is also associated with walking and biking to school $[77,78,82]$. About $74.6 \%$ of the parents prefer driving their children to school because it is on his/her way to work.

More than $87.5 \%$ of parents note that the culture of walking or biking to schools in Abu Dhabi is not strong. In addition, $79.8 \%$ of them feel that the driving public (traffic) are not used to slowing down during student crossings. This factor had the highest mean (3.837) compared to the means of all other thirteen factors affecting parent's decision to allow their children to walk or bike to school. In many countries, a school zone speed limit is applied and has become the culture. It should be noted that restricted speed limits for school zones is a new concept in the city of Abu Dhabi. However, looking at the fine categories for motorists in Abu Dhabi (on the Abu Dhabi traffic website: http://adpolics.gov.ae), there is no mention of fines related to exceeding speed limits in school zones. In addition, most school zones have no signs to identify the area as a school zones. There are no speed limit signs for most of these areas or zones.

The relatively high mean scores of parents' responses with regard to children's way to school to be unsafe is likely to further contribute to the low levels of active commuting. Safety concerns of parents were mostly related to road conditions (71.4\% and 63.3\%), community conditions (46.1\%, 58.5\%, and 45.3\%) and traffic conditions (68.2\% and $48.2 \%)$. This is relatively in line with other studies (e.g. from the UK, where $90 \%$ of the parents of 6- to 10-year-old children were worried about safety issues and $89 \%$ because of traffic [76]; and over $40 \%$ of parents restricted schoolchildren aged $7-11$ years from coming home alone from school because of traffic danger, while around $20 \%$ of parents enforced this restriction due to other safety issues [26].

Even though, the most significant determinants of mode of travel to school are perceived "stranger danger", or danger of assault in many studies [51,57-59], the summated score of community safety in Abu Dhabi received a favorable score from parents. In addition, community score related to safety was not seen as a determining factor in a parents' decision. Consistent with results from other studies [45,65], the environment (weather conditions, car pollution [71,83], smog) appears to exert a significant effect on mode of travel to school.

Abu Dhabi research is consistent with other studies that distance is a critical factor in children's travel walk [42,44,52]. Most children live 5 to 15 kilometers from their schools, taking them more than 30 minutes to get there. Such a distance might not encourage any parent to allow their children to walk or bike to school. Many land authorities in Abu Dhabi argue the lack of space available in the Abu Dhabi Island to build schools. On the other hand, many education strategists in ADEC argue that "community" schooling would not be effective if the land authorities do not take the initiatives to convert many business or residential blocks of land to be used as schools in the future. Consistent with other studies [7,54, 55], neighborhood aesthetics and characteristics, related to walking or bicycle lanes, and sidewalks have significant effect on the mode of travel. Regardless of whether sidewalks are improved, or bicycle lanes are provided, parents do not feel too enthusiastic about letting their children walk or bike to school.

If we isolate the sample of parents who use the family car as a mode of transportation to school, we note that $87.6 \%$ of them gave a score of "strongly disagree" or "disagree" on their decision to allow the child to walk or bike to school. In addition, for this group only, the correlation between their infrastructure score and the culture of walking score or biking score is $94.5 \%$. This might suggest that the factor of absence of a culture of walking or biking might have a strong biasing effect on other factors such as infrastructure of route to school. 
In spite of many research studies suggesting that active commuting to school is an opportunity for children to achieve regular daily physical activity and lowering their health risks $[3,4,13,29]$, results of the current study do not provide significant support of parents' belief of the health values of walking or biking to school. Research results have been inconsistent showing that boys are more likely to walk to school in comparison to girls [19,22,52,68,75,80]. In Abu Dhabi, both parent's gender and children's gender are significant determinants of the decision to allow children to walk or bike to schools.

For those walking or biking to schools, boys constitute about $73.8 \%$. One might expect that boys might be more allowed to walk or bike to school in a conservative society such as the United Arab Emirates. With regard to children's age, Abu Dhabi findings show that younger children are more likely to walk to school. Such results are consistent with other findings [21,48]. In Abu Dhabi, results show that about $62.3 \%$ of those that walk or bike to school are from grade 1 to grade 5 .

Inconsistent with other studies, household income appears insignificant in the decision to allow the child to walk or bike to school. Others found household income to be a potential factor $[52,82]$. Nevertheless, if we isolate the children that walk or bike to school, we note that for those with a household monthly income below (4000\$), about $12.4 \%$ walk or bike to school. However, for those with a household monthly income around $(11,000 \$)$, only $3.9 \%$ walk or bike to school. Meanwhile, if we isolate those that use a car to school, we note that for those with a household monthly income below (4000\$), about 40.2\% use a car. However, for those with a household monthly income around (11,000\$), about 53.1\% use a car.

Other household factors such as car ownership and parents driving to work both affect mode choice or decision of parents. This result is consistent with results from other studies [75]. The only yardstick related to ethnic background in the Abu Dhabi study is parent's nationality. This factor had a significant effect on the decision of parents. Other studies also found ethnic background to be significant [22,50,51].

Results verify McDonald $[75,76]$ results obtained showing how household interactions affect walking and biking to school; and how parental employment status and commuting patterns affect school travel. He found that parents who commute to work in the morning are less likely to have the majority of parents believe that the schools do not offer such teaching skills. Many studies have recognized the responsibility of schools for providing adequate walking or biking to school skills to children along with teaching them the benefits of those functions [39, $40,79]$. As a matter of fact, in a separate survey of principals in Abu Dhabi city schools, only $5.4 \%$ of principals mentioned that their schools provide some form of learn- ing related to the benefits of walking generally.

\section{CONCLUSIONS}

Current conditions in Abu Dhabi City are not conducive to active travel to school. Our main research objecttive was to better understand the context within which active travel to school occurs in Abu Dhabi, with a focus on the viewpoint of parents. The instrument used has largely depended on previous literature that has looked at the influence of many factors on how children travel to school. Parents are thus the focus of our analysis. Our objective was to understand how they see active travel, in particular with regard to the trip to school, and how other familial factors might interfere with their decision to allow the child to walk or bike to school.

Research has shown that the most successful way to increase bicycling and walking is through a comprehendsive approach that includes aggressive strategies (i.e. the "5 E's": education, encouragement, engineering, enforcement, and evaluation). Such programs should follow comprehensive strategies focusing on infrastructure improvements where the physical environment is not conducive to walking or bicycling, and promoting noninfrastructure programs, including education, encouragement and enforcement strategies.

In 2008, Abu Dhabi embarked on an aggressive strategic plan of education reform that included the design and implementation of school facilities that incorporate the concepts of community schooling. From a transportation perspective, the location of community schools should affect trip lengths by decreasing the distance from home to school. Therefore to understand how a shift to community schools might affect walking behavior among children. However, many questions remain unanswered by the Abu Dhabi authorities involved in school location and allocation planning.

The new schools are of the highest quality when it comes to the design and internal layouts; however, they are still located in areas that witness challenging children who walk or bike to school after controlling for individual, household, and neighborhood factors. The Abu Dhabi study also suggests that $69.5 \%$ of the parents are willing to allow their child to walk to school if they are in a group or accompanied by an adult. In such instances, McDonald [48,50,75,76] suggests that policymakers may therefore want to create programs that allow parents to share chaperoning responsibilities for the school trip to address parental time constraints.

With regard to children's walking or biking skills and the school's efforts to teach those skills to children, the researcher of this study found that factors such as distances, built environment, community atmospheres, unsafe roads and crossings that might make them "half- 
community” schools, as phrased by a parent responding to the survey. As McDonald [50] suggests, decision makers should investigate many scenarios when it comes to walking or biking to schools in the morning. School planners should envision scenarios that could specify each student's distance to school and the circumstances surrounding the trips. Such scenario building ideas could provide realistic understanding of the sensitivity of walking or biking to school.

For Abu Dhabi, active travel to school will not be effective unless the walking and biking environment is radically transformed. In addition, a radical change in the culture of active travel to school is needed if parents are to trust the education decision makers, the road authorities, the community norms, and the government policies to encourage students to actively travel to school. The existing urban forms in Abu Dhabi City are dangerous, and increasing the number of children pedestrians and cyclists will simply increase the risk of accidents unless the whole culture of travel and urban environment is radically modified. The organization of city space related to school location and allocation must be rethought to increase children's safety. This means that a more radical approach is required. Changes must be made along the entire route children are likely to take to get to school, and this must be done in every neighborhood.

A more comprehensive approach is required that will increase a neighborhood's walk-ability for everyone (a cultural impact), not just school students. If the desire is to increase the proportion of children to walk to school, other people will have to walk more too. A cultural change means also that there must be changes in the behavior of the entire stakeholders of the road system, the drivers, pedestrians and cyclists. McMillan [46] recommended an integrative framework of mediating factors which includes neighborhood safety [(real/perceived), traffic safety (real/perceived), and household transportation options. The framework also has some moderating factors that include social/cultural norms, parental attitudes, and socio-demographics], which are affected by urban form, parental decision-making, and children travel behavior to school.

There are several limitations that have to be considered in the current study. Most of the questions used the phrase "walking or biking": Most parents might have had different perceptions with regard to each mode of travel and not the same. Future studies should have separate questions for each mode of travel. The study relied strictly on the opinion of parents. Future studies might try to solicit the opinion of children going to school too. In the current study, the non-UAE parents (from a Western background) are underrepresented. This might limit the generalization of the findings to the whole population living in Abu Dhabi (proportion of non-UAE. The cur- rent study concentrated on the City of Abu Dhabi. It would be desirable in the future to include cities or communities with different levels of the built environment such as $\mathrm{Al}$ Ain and Gharbia.

This research adds to our understanding of how different variables and familial features influence parents' choices related to the children's mode of travel to school.

\section{ACKNOWLEDGEMENTS}

This research is funded and supported fully by the Abu Dhabi Education Council. We would like to thank ADEC's Director General and staff, region managers and staff, school principals, supervisors, managers, consultants, students and teachers for their Full support. We would also like to thank all parents who answered our call and participated in this study.

\section{REFERENCES}

[1] Mota, J., Almeida, M., Santos, P. and Ribeiro, J. (2005) Perceived neighborhood environments and physical activity in adolescents. Preventive Medicine, 41, 834-836. doi:10.1016/j.ypmed.2005.07.012

[2] Mota, J., Gomes, H., Almeida, M., Ribeiro, J., Carvalho, J. and Santos, M. (2007) Active versus passive transportation to school-Differences in screen time, socio-economic position and perceived environmental characteristics in adolescent girls. Annals of Human Biology, 34, 273-282. doi:10.1080/03014460701308615

[3] Andersen, L., Harro, M. and Sardinha, L. (2006) Physical activity and clustered cardiovascular risk in children: A cross-sectional study (The European youth heart study). Lancet, 368, 299-304. doi:10.1016/S0140-6736(06)69075-2

[4] Bringolf-Isler, B., Grize, L., Mäder, U., Ruch, N., Sennhauser, F. and Braun-Fahrländer, C. (2008) Personal and environmental factors associated with active commuting to school in Switzerland. Preventive Medicine, 46, 67-73. doi:10.1016/j.ypmed.2007.06.015

[5] Staunton, C., Hubsmith, D. and Kallins W. (2003) Promoting safe walking and biking to school: The marin county success story. American Journal of Public Health, 93, 1431-1434. doi:10.2105/AJPH.93.9.1431

[6] Cooper, A., Andersen, L., Wedderkopp, N., Page, A. and Froberg, K. (2005) Physical activity levels of children who walk, cycle, or are driven to school. American Journal of Preventive Medicine, 29, 179-184. doi:10.1016/j.amepre.2005.05.009

[7] Boarnet, M., Anderson, C., Day, K., McMillan, T. and Alfonzo, M. (2005) Evaluation of the California safe routes to school legislations: Urban form changes and children's active transportation to school. American Journal of Preventive Medicine, 28, 134-140. doi:10.1016/j.amepre.2004.10.026

[8] Cooper, A., Page, A., Foster, L. and Qahwaji, D. (2003) Commuting to school: Are children who walk more physically active? American Journal of Preventive Medicine, 25, 273-276. doi:10.1016/S0749-3797(03)00205-8 
[9] Department of the Environment, Transport and the Regions (DETR) (1998) Transport statistics report, national travel survey 1995/97.

[10] Sleap, M. and Warburton, P. (1993) Are primary school children gaining heart health benefits from their journeys to school? Child Care Health Development, 19, 99-108. doi:10.1111/j.1365-2214.1993.tb00717.x

[11] Sustrans, S. (1999) Safe routes to schools (Bristol: Sustrans), information sheet, FS01.

[12] Transportation Alternatives (2002) The 2002 summary of safe routes to school programs in the United States. Transportation Alternatives, New York.

[13] Tudor-Locke, C., Ainsworth, B. and Popkin, B. (2001) Active commuting to school an overlooked source of children's' physical activity? Sports Medicine, 31, 309-313.

[14] Seaton, J. and Wall, S. (2001) A summary of Walkers and walking in the Perth metropolitan region. Walking in the 21st Century, Perth.

[15] Kowey, B. (1999) The journey to school: Making it safer by reducing traffic at school sites and increasing pedestrian and driver education opportunities. Proceedings of the 11th Canadian Multidisciplinary Road Safety Conference, Halifax, 9-12 May 1999, 222-229.

[16] Rojas-Guyler, L., Sparks, J. and King, K. (2007) School principals' perceptions of students walking and bicycling to school. Californian Journal of Health Promotion, 5, 5161.

[17] Pabayo, R. and Gauvin, L. (2008) Proportions of students who use various modes of transportation to and from school in a representative population-based sample of children and adolescents, 1999. Preventive Medicine, 46, 6366. doi:10.1016/j.ypmed.2007.07.032

[18] Sirard, J., Riner, Jr., W., McIver, K. and Pate, R. (2005) Physical activity and active commuting to elementary school. Medicine and Science in Sports and Exercise, 37, 2062-2069. doi:10.1249/01.mss.0000179102.17183.6b

[19] Carlin, J., Stevenson, M., Roberts, I., Bennett, C., Gelman, A. and Nolan, T. (1997) Walking to school and traffic exposure in Australian children. Aust. New Zealand Journal of Public Health, 21, 286-292. doi:10.1111/j.1467-842X.1997.tb01701.X

[20] Ham, S., Macera, C. and Lindley, C. (2005) Trends in walking for transportation in the United States, 1995 and 2001. Preventing Chronic Disease, 2, A14.

[21] Hillman, M., Adams, J. and Whitelegg, J. (1990) One false move: A study of children's independent mobility. PSI Publishing, London.

[22] Bricker, S., Kanny, D., Mellinger-Birdson, A., Powell, K. and Shisler, J. (2002) School transportation modes-Georgia. Morbidity and Mortality Weekly Report, 51, 704-705.

[23] Salmon, J., Timperio, A., Cleland, V. and Venn, A. (2005) Trends in children's physical activity and weight status in high and low socio-economic status areas of Melbourne, Victoria, 1985-2001. New Zealand Journal of Public Health, 29, 337-342. doi:10.1111/j.1467-842X.2005.tb00204.x

[24] Cooper, A., Wedderkopp, N., Wang, H., Andersen, L., Froberg, K. and Page, A. (2006) Active travel to school and cardiovascular fitness in Danish children and adolescents. Medical Science and Sports Exercise, 38, 17241731. doi:10.1249/01.mss.0000229570.02037.1d

[25] Roberts, I., Carlin, J., Bennett, C., Bergstrom, E., Guyer, B. and Nolan, T. (1997) An international study of the exposure of children to traffic. Injury Prevention, 3, 89-93. doi:10.1136/ip.3.2.89

[26] Hillman, M., Adams, J. and Whitelegg, J. (1990) One false move: A study of children's independent mobility Policy Studies Institute, London.

[27] Dellinger, A. (2005) Barriers to children walking to or from school-United States, 2004. Morbidity and Mortality Weekly Report, 54, 949-952.

[28] Department for Transport (2006) Transport statistics bul0 letin: National travel survey: 2005. Department of Transport, London.

[29] Biddle, S., Gorely, T., and Stensel, D. (2004) Health-enhancing physical activity and sedentary behaviour in children and adolescents. Journal of Sports Science, 22, 679701. doi:10.1080/02640410410001712412

[30] Tudor-Locke, C., Ainsworth, B.E., Adair, L. and Popkin, B.M. (2003) Objective physical activity of Filipino youth stratified for commuting mode to school. Medical Science Sports Exercise, 35, 465-471. doi:10.1249/01.MSS.0000053701.30307.A6

[31] Ziviani, J., Scott, J. and Wadley, D. (2004) Walking to school: Incidental physical activity in the daily occupations of Australian children. Occupational Therapy International, 11, 1-11. doi:10.1002/oti.193

[32] Steinbeck, K. (2001) The importance of physical activity in the prevention of overweight and obesity in childhood: A review and an opinion. Obesity Reviews, 2, 117-130. doi:10.1046/j.1467-789x.2001.00033.x

[33] Kirby, J. and Inchley, J. (2008) Active travel to school: Views of 10-13 year old schoolchildren in Scotland. Health Education, 109, 169-183. doi:10.1108/09654280910936611

[34] Saksvig, B., Catellier, D., Pfeiffer, K., Schmitz, K., Conway, T., Going, S., Ward, D., Strikmiller, P. and Treuth, M. (2007) Travel by walking before and after school and physical activity among adolescent girls. Archives of Pediatric and Adolescent Medicine, 161, 153-158. doi:10.1001/archpedi.161.2.153

[35] Rosenberg, D., Salli,s J., Conway, T., Cain, K. and McKenzie, T. (2006) Active transportation to school over 2 years in relation to weight status and physical activity. Obesity, 14, 1771-1776. doi:10.1038/oby.2006.204

[36] Riddoch, C., Andersen, L., Wedderkopp, Harro, M., Klasson-Heggebø, L., Sardinha, L., Cooper, A. and Ekelund, U. (2004) Physical activity levels and patterns of 9 and 15 year old European children. Medical Science Sport Exercise, 36, 86-92.

doi:10.1249/01.MSS.0000106174.43932.92

[37] Tudor-Locke, C., Neff, L., Ainsworth, B., Addy, C. and Popkin, B. (2002) Omission of active commuting to school and the prevalence of children's health-related physical activity levels: The Russian longitudinal monitoring study. Child Care Health Development, 28, 507-512. doi:10.1046/j.1365-2214.2002.00295.X 
[38] Metcalf, B., Voss, L., Jeffery, A., Perkins, J. and Wilkin, T. (2004) Physical activity cost of the school run: Impact on schoolchildren of being driven to school. British Medical Journal, 329, 832-833. doi:10.1136/bmj.38169.688102.F71

[39] McMillan, T. (2003) Walking and urban form: Modeling and testing parental decisions about children's travel. Unpublished Doctoral Dissertation, University of California, Irvine.

[40] McMillan, T. (2007) The relative influence of urban form on a child's trip to school. Transportation Research Part A: Policy and Practice, 41, 69-79. doi:10.1016/j.tra.2006.05.011

[41] McMillan, T. (2005) Urban form and a child's trip to school: The current literature and a framework for future research. Journal of Planning Literature, 19. 440-456. doi: $10.1177 / 0885412204274173$

[42] Schlossberg, M., Greene, J., Phillips, P., Johnson, B. and Parker, B. (2006) Effects of urban form and distance on travel mode. Journal of the American Planning Association, 72, 337-346. doi:10.1080/01944360608976755

[43] Black, C., Collins, A. and Snell, M. (2001) Encouraging walking: The case of journey-to-school trips in compact urban areas. Urban Studies, 38, 1121-1141. doi:10.1080/00420980124102

[44] Timperio, A., Ball, K., Salmon, J., Roberts, R., GilesCorti, B., Simmons, D., Baur, L. and Crawford, D. (2006) Personal, family, social, and environmental correlates of active commuting to school. American Journal of Preventive Medicine, 30, 45-51. doi:10.1016/j.amepre.2005.08.047

[45] Ewing, R., Scbroeer, W. and Greene, W. (2004) School location and student travel analysis of factors affecting mode choice. Journal of the Transportation Research Board, 1895, 55-63. doi:10.3141/1895-08

[46] McMillan, T., Day, K. and Boarnet, M. (2006) Johnny can walk to school-Can Jane? Examining sex differences in children's active travel to school. Children, Youth and Environment, 16, 75-89.

[47] Cohen, D., Ashwood, S. and Scott, M. (2006) Proximity to school and physical activity among middle school girls: The trial of activity for adolescent girls study. Journal of Physical Activity and Health, 3, S124-S133.

[48] McDonald, N. (2007) Active transportation to school: Trends among US schoolchildren, 1969-2001. American Journal of Preventive Medicine, 32, 509-516. doi:10.1016/j.amepre.2007.02.022

[49] Martin, S. and Carlson, S. (2005) Barriers to children walking to and from school: United States, 2004. Journal of the American Medical Association, 294, 2160-2162. doi:10.1001/jama.294.17.2160

[50] McDonald, N. (2007) Travel and the social environment: evidence from Alameda county, California. Transportation Research Part D: Transport and Environment, 12, 53-63. doi:10.1016/j.trd.2006.11.002

[51] Zhou, H., Yang, J., Hsu, P. and Chen, S. (2010) Factors affecting students' walking/biking rates: Initial findings from a safe route to school survey in Florida. Journal of
Transportation Safety \& Security, 2, 14-27. doi:10.1080/19439960903564819

[52] Kerr, J., Rosenberg, D., Sallis, J., Saelens, B., Frank, L. and Conway, T. (2006) Active commuting to school: Associations with environment and parental concerns. Medicine and Science in Sports and Exercise, 38, 787-794. doi:10.1249/01.mss.0000210208.63565.73

[53] Merchant, A., Dehghan, M., Behnke-Cook, D. and Anand, S. (2007) Diet, physical activity, and adiposity in children in poor and rich neighbourhoods: A crosssectional comparison. Nutrition Journal, 6. www.nutritionj.com/content/6/1/1

[54] Ewing, R., Forinash, C. and Schroeer, W. (2005) Neighborhood schools and sidewalk connections: What are the impacts on travel mode choice and vehicle emissions? Transportation Research News, 237, 4-10.

[55] Joshi, M. S. and MacLean, M. (1995) Parental attitudes to children's journeys to school. World Transport Policy and Practice, 1, 29-36. doi:10.1108/13527619510102016

[56] Tranter, P. and Doyle, J. (1996) Reclaiming the residential street as play space. International Play Journal, 4, 81-97.

[57] Tranter, P. and Pawson, E. (2001) Children's access to local environments: A case study of Christchurch, New Zealand. Local Environment, 6, 27-48. doi:10.1080/13549830120024233

[58] Martin, S. and Carlson, S. (2005) Barriers to children walking to or from school-United States, 2004. Morbidity and Mortality Weekly Report, 54, 949-952.

[59] Parisi, D. and Hondorp, B. (2005) Transportation professsionals get involved with safe routes to school. Institute of Transportation Engineers Journal, 75, 41-46.

[60] Vincent, J. (2006) Public schools as public infrastructure: Roles for planning researchers. Journal of Planning Education and Research, 25, 433-437. doi:10.1177/0739456X06288092

[61] Chung, C. (2002) Using public schools as communitydevelopment tools: Strategies for community-based developers. Joint Center on Housing Studies of Harvard University and Neighborhood Reinvestment Corporation, Cambridge.

[62] Saelens, B., Sallis, J. and Frank, L. (2003) Environmental correlates of walking and cycling: Findings from the transportation, urban design, and planning literatures. Annals of Behavioral Medicine, 25, 80-91. doi:10.1207/S15324796ABM2502_03

[63] Ridgewell, C., Sipe, N. and Buchanan, N. (2009) School travel modes: Factors influencing parental choice in four Brisbane schools. Urban Policy and Research, 27, 43-57. doi:10.1080/08111140802304793

[64] Braza, M., Shoemaker, M. and Seeley, A. (2004) Neighborhood design and rates of walking and biking to elementary school in thirty-four California communities. American Journal of Health Promotion, 19, 128-136. doi:10.4278/0890-1171-19.2.128

[65] Catford, J. and Caterson, I. (2003) Snowballing obesity: Australians will get run over if they just sit there. Medical Journal of Australia, 179, 577-579.

[66] O’Brien, C. (2003) Transportation that's actually good for 
the soul. National Center for Bicycling and Walking (NCBW) (Canada), 54, 1-13.

[67] Morris, J., Wang, F. and Lilja, L. (2001) School children’s travel patterns: A look back and a way forward. 24th Australasian Transport Research Forum, Hobart.

[68] Engwicht, D. (1992) Towards an eco-city: Calming the traffic. Envirobook, Sydney.

[69] Collins, D. and Kearns, R. (2001) The safe journeys of an enterprising school: Negotiating landscapes of opportunity and risk. Health Place, 7, 293-306. doi:10.1016/S1353-8292(01)00021-1

[70] Tranter, P. (1993) Children's mobility in Canberra: Confinement or independence? Monograph Series No. 7 (Canberra: Department of Geography and Oceanography, University College, Australian Defense Force Academy, University of New South Wales).

[71] Deilinger, A. and Staunton, C. (2002) Barriers to children walking and bicycling to scbool: United States 1999. Morbidity and Mortality Weekly, 51, 701-704.

[72] Merom, D., Tudor-Locke, C., Bauman, A. and Rissel, C. (2005) Active commuting to school among NSW primary school children: Implications for public health, Health Place.

[73] Merom, D., Tudor-Locke, C., Bauman, A. and Rissel, C. (2006) Active commuting to school among NSW primary school children: Implications for public health. Health Place, 12, 678-687. doi:10.1016/j.healthplace.2005.09.003

[74] DiGuiseppi, C., Robert, I., Li, L. and Allen, D. (1998) Determinants of car travel on daily journeys to school: Cross sectional survey of primary school children. British Medical Journal, 316, 1426. doi:10.1136/bmj.316.7142.1426

[75] McDonald, N. (2008) Children's mode choice for the school trip: The role of distance and school location in walking to school. Transportation, 35, 23-35. doi:10.1007/s11116-007-9135-7

[76] McDonald, N. (2008) Critical factors for active transportation to school among low-income and minority students evidence from the 2001 national household travel survey. American Journal of Preventive Medicine, 34, 341-344. doi:10.1016/j.amepre.2008.01.004
[77] Martin, S., Lee, S. and Lowry, R. (2007) National prevalence and Correlates of walking and bicycling to school. American Journal Preventive Medicine, 33, 98-105. doi:10.1016/j.amepre.2007.04.024

[78] Evenson, K., Huston, S., McMillen, B., Bors, P. and Ward, D. (2003) Statewide prevalence and correlates of walking and bicycling to scbool. Archives of Pediatrics \& Adolescent Medicine, 157, 887-892.

[79] Yung, J. Wearing, S. and Hills, A. (2008) Child transport practices and perceived barriers in active commuting to school. Transportation Research: Part A, Policy and Practice, 42, 895-900. doi:10.1016/j.tra.2007.12.007

[80] Yarlagadda, A. and Sivaramakrishnan, S. (2007) Modeling children's school travel mode and parental escort decisions. The 86th Annual Meeting of the Transportation Research Board, Transportation Research Board of the National Academies, Washington, DC.

[81] Zhao, F., Chow, L.-F., Li, M.-T., Ubaka, L. and Gan, A. (2003) Forecasting transit walk accessibility: A regression model alternative to the buffer method. Transportation Research Record, 1835, 34-41. doi:10.3141/1835-05

[82] Grize, L., Bringolf-Isler1, B., Martin, E. and BraunFahrländer1, C. (2010) Trend in active transportation to school among Swiss school children and its associated factors: Three cross-sectional surveys 1994, 2000 and 2005. International Journal of Behavioral and Nutrition Activity, 7, 1-8.

[83] Salvesen, D. and Hervey, P. (2003) Good schools-Good neighborhoods: The impacts of state and local school board policies on the design and location of schools in North Carolina (CURS Report No. 2003-03). Center for Urban and Regional Studies, University of North Carolina at Chapel Hill, Chapel Hill.

[84] Spallek, M., Turner, C., Spinks, A., Bain, C. and McClure, R. (2006) Walking to school: Distribution by age, sex and socio-economic status. Health Promotion Journal of Australia, 17, 134-138.

[85] Alexander, L., Inchley, M., Todd, J., Currie, D., Cooper, A. and Currje, C. (2005) The broader impact of walking to school among adolescents: Seven day accelerometer based study. British Medical Journal, 33, 1061-1062. doi:10.1136/bmj.38567.382731.AE 